\begin{tabular}{|l|l|}
\hline $\begin{array}{l}\text { Postprint } \\
\text { Version } \\
\text { Journal website }\end{array}$ & 1.0 \\
\hline \begin{tabular}{l} 
Pubmed link://www.pec-journal.com/article/S0738-3991\%2898\%2990048-9/abstract \\
\hline DOI
\end{tabular} & $10.1016 /$ S0738-3991(98)90048-9 \\
\hline
\end{tabular}

This is a NIVEL certified Post Print, more info at http://www.nivel.eu

\title{
Patients' Socioeconomic Status in Physical Therapy: Expectations and Behaviors
}

WiLlem BosVeld (A), BRITT D. SPAAN, EMMY M. SLUIJS.

(a) Netherlands institute of primary health care, p.o. box 1568, 3500 BN Utrecht, The Netherlands.

Introduction. In this paper we report on a study regarding the interaction between physical therapists and their patients against the background of patients' socioeconomic status (SES). From an earlier study (Zuijderduin et al., 1995) it is known that patients' SES is related to the number of therapy sessions patients receive. Lower educated patients received on average 15 sessions of physical therapy, whereas higher educated patients received on average 10 sessions. From other disciplines (e.g. psychotherapy, general practise) it is known that patients' SES affects doctors' expectations about, for example, recovery. In the present study it is expected that patients' SES is related to expectations and prognoses held by therapists, patient behavior (i.e. coping strategies) and patients' prognoses about their recovery.

Method. 84 physical therapist completed registration forms on 1837 patients and asked permission to make audio recordings. Patients filled in a questionnaire.

Results. Patients' SES was positively related to therapists' expectations about the course of illness and cooperation, and time spent on patients, controlled for patients' age and their health status. Patients' SES was positively related to their own expectations about recovery and negatively related to self-reported pain and perceived hinderance. Further, SES was positively related to the number of questions asked by patients.

Conclusion. These results may indeed point at the differences in number of sessions, as a function of SES. Further, whereas the present study was aimed at the process of treatment, future studies should also aim at the role of patients' SES in the outcome of treatment in physical therapy. 